\title{
Leukotrienes B4, C4, D4 and E4 in the Exhaled Breath Condensate (EBC), Blood and Urine in Patients with Pneumoconiosis
}

\author{
Daniela PELCLOVÁ ${ }^{1 *}$, Zdenka FENCLOVÁ ${ }^{1}$, Štěpánka VLČKOVÁ ${ }^{1}$, Jindřiška LEBEDOVÁ , $^{\text {, }}$ \\ Kamila SYSLOVÁ ${ }^{2}$, Ondřej PECHA ${ }^{3}$, Jaromír BĚLÁČEK ${ }^{3}$, Tomáš NAVRÁTIL ${ }^{4}$, \\ Marek KUZMA ${ }^{5}$ and Petr KAČER ${ }^{2}$ \\ ${ }^{1}$ Department of Occupational Medicine of the 1st Faculty of Medicine, Charles University in Prague and General \\ University Hospital, Czech Republic \\ ${ }^{2}$ Institute of Chemical Technology, AS CR, v. v. i., Czech Republic \\ ${ }^{3}$ Institute of Informatics of the 1st Faculty of Medicine, Charles University in Prague and General University \\ Hospital, Czech Republic \\ ${ }^{4}$ J. Heyrovský Institute of Physical Chemistry, AS CR, v. v. i., Czech Republic \\ ${ }^{5}$ Institute of Microbiology, AS CR, v. v. i., Czech Republic
}

Received January 11, 2011 and accepted May 17, 2012

Published online in J-STAGE June 13, 2012

\begin{abstract}
Leukotrienes (LTs) are involved in the pathogenesis of lung fibrosis and were increased in exhaled breath condensate (EBC) of the patients with pneumoconiosis. However the possible influence of extra-pulmonary disorders on the EBC markers is not known. Therefore in parallel with EBC, LTs' levels in the plasma and urine were measured in patients with pneumoconiosis (45 $\times$ asbestos exposure, $37 \times$ silica exposure) and in 27 controls. Individual LTs B4, C4, D4 and E4 were measured by liquid chromatography - electrospray ionization - tandem mass spectrometry (LC-ESI-MS/MS). In EBC, LT D4 and LT E4 were increased in both groups of patients $(p<0.001$ and $p<0.05$ ), comparing with the controls. Both LT B4 and cysteinyl LTs were elevated in asbestosexposed subjects $(p<0.05)$. Asbestosis with more severe radiological signs $(\mathbf{s 1} / \mathbf{s} 2-\mathbf{t} 3 / \mathbf{u} 2)$ and lung functions impairment has shown higher cysteinyl LTs and LT C4 in the EBC $(p<0.05)$ than mild asbestosis (s1/s0-s1/s1). In addition, in the subjects with asbestosis, cysteinyl LTs in EBC correlated with TLC $(-0.313, p<0.05)$ and TLCO/Hb $(-0.307, p<0.05)$, and LT C4 with TLC $(-0.358, p<0.05)$. In pneumoconioses, $\mathrm{EBC}$ appears the most useful from the 3 fluids studied.
\end{abstract}

Key words: Leukotrienes, Lung fibrosis, Exhaled breath condensate, Plasma, Urine, Silicosis, Asbestosis, SPE, LC-ESI-MS/MS

*To whom correspondence should be addressed.

E-mail: daniela.pelclova@LF1.cuni.cz

(C)2012 National Institute of Occupational Safety and Health

\section{Introduction}

In the latest several years, the analysis of biomarkers present in the exhaled air has inspired a number of developments, appearing to be a beneficial none-invasive diagnostic tool for monitoring the activity of respiratory 
system disorders. In occupational pneumology, different biomarkers of the effect, such as oxidative stress and inflammatory-derived markers have been applied in the investigation of asthma and pneumoconiosis, which may contribute to studying the pathological state of the lungs of workers with previous exposure to fibrogenic and carcinogenic dusts, such as asbestos and silica ${ }^{1}$. For patients with asbestosis and silicosis, no treatment is available, and a chronic progression is typical even decades after the end of exposure due to the retention of fibrogenic particles in the lungs. Several diseases may develop due to asbestos exposure, besides pleural plaques and diffuse pleural thickenings also malignant tumors such as lung cancer and mesothelioma of the pleura, which have a poor prognosis. Silica is also a recognized lung carcinogen according to the International Agency for Research on Cancer (IARC).

The oxidation of arachidonic acid by the 5-lipoxygenase pathway produces leukotrienes (LTs), playing an active role in the pathogenesis of respiratory disorders. There appear to be diseases where the 5-lipoxygenase pathway is constitutively activated and LTs are produced constantly, as in idiopathic pulmonary fibrosis ${ }^{2}$ and systemic sclerosis ${ }^{3)}$.

LTs are involved in the pathogenesis of lung fibrosis by direct effects on migration, proliferation and matrix protein synthesis by fibroblasts, as well as by indirect effects, such as suppression of the production of antifibrogenic cytokines $^{4}$. LT B4 attracts and activates leukocytes and its level increases during exacerbation of chronic obstructive pulmonary disease (COPD) and after smoking ${ }^{5)}$. Cysteinyl LTs (C4, D4 and E4) participate in the pathogenesis of asthma $^{6,7)}$ and are active in the remodeling of the airways. They promote the proliferation of human bone marrowderived fibroblasts, which participate in tissue remodeling and repair ${ }^{8}$. Also human bronchial fibroblasts can produce both LT B4 and cysteinyl LTs ${ }^{9}$. Hypoxia-induced chronic pulmonary hypertension ${ }^{10)}$ and bleomycin-induced pulmonary fibrosis in mice are characterized by overproduction of cysteinyl LTs and are significantly ameliorated in 5-lipoxygenase knockout mice ${ }^{11)}$.

The experimental study of Shimbori et al. ${ }^{12)}$ recently proved the role of LTs in silica-induced pulmonary fibrosis in mice. They found that the tissue content of LT B4 and cysteinyl LTs after silica exposure was markedly elevated in the acute phase, then decreased and increased again in the chronic phase. Based on their histological findings they suggest that fibroblasts and type II alveolar epithelial cells, able to secrete LTs, play an important role in the chronic phase of silica-induced fibrogenesis and that the increased production of LTs in lung tissues contributes to the onset and progression of fibrosis.

Several clinical studies are in agreement with the experimental results. It was shown that patients with idiopathic pulmonary fibrosis exhibit overproduction of both LT B4 and cysteinyl $\mathrm{LTs}^{13,}{ }^{14)}$. LT B4 ${ }^{15)}$ and cysteinyl LTs were also elevated in the EBC of patients with pneumoconio$\operatorname{ses}^{16,17)}$

However, LTs do not originate exclusively in the lungs, as arachidonic acid is contained in the membrane phospholipids of all cells in the body. LTs are analogous to hormones that act locally and are considered as chemical messengers that transmit signals from immune system cells to essentially all other types of cells in the surrounding tissues ${ }^{18)}$. LT B4 is best known for its role in initiating the inflammatory response, produced by leukocytes (e.g. macrophages) residing in the tissue in response to stimuli like infection or stress. It has been found to be overproduced in ulcerative colitis, Crohn's disease, inflammatory bowel disease, rheumatoid arthritis and other disorders ${ }^{18)}$. Recently, roles of LTs' have been discovered in different kinds of cancers, atherosclerosis and other disorders ${ }^{19)}$, and these findings might contribute to the treatment of these diseases in the future ${ }^{20,21)}$.

$\mathrm{EBC}$ is usually considered to indicate lung involvement only. However, as was shown recently in subjects with human carcinogen group 1 (IARC) 2,3,7,8-tetrachloro-dibenzo-p-dioxin (TCDD) induced atherosclerosis, vascular dysfunction and neurotoxicity, EBC may reflect other then lung diseases. These patients without respiratory disorders had not only urine, but also EBC concentration of LTs' significantly increased ${ }^{22)}$. Therefore, this study was also aimed to exclude a significant extra-pulmonary involvement of atherosclerosis and other systemic diseases on the EBC markers in subjects with asbestosis and silicosis.

As was already mentioned, besides in the EBC, LTs can be detected in other body fluids, such as plasma and urine, using sensitive analytical methods. Surprisingly little is known about whether a correlation among blood, urine and $\mathrm{EBC}$ concentrations exists, as LTs have usually been studied in a single matrix only. Moreover, as cysteinyl LTs have been most frequently analyzed by enzyme immunoassay (EIA) as a complex of LT C4, LT D4 and LT E4, little information is available on their individual levels. LT E4 is considered to be the final metabolite of LT C4 and LT D4. Consequently, only LT E4 has commonly been analyzed in urine ${ }^{23,24)}$.

Therefore, in the present study, a measurement of all the above mentioned markers in the EBC, plasma and urine was performed to evaluate the possible impact of systemic 
diseases, pharmaceuticals and diet on EBC levels of LTs, and, on the other hand, the potential correlation of respiratory disorders with plasma and urine LTs' levels.

\section{Methods}

\section{Subjects}

In total, 82 patients (60 men, 22 women) with occupational lung diseases were enrolled in the study. Fortyfive patients ( 24 men, 21 women, mean age $69.6 \pm 2.0 \mathrm{yr}$; $15.5 \%$ smokers) had been exposed to asbestos for $23.3 \pm 2.9$ $\mathrm{yr}$, on average, in the production of asbestos insulation and textile materials, asbestos cement roofing and pipe. Chest radiography was performed in all asbestos-exposed subjects, and high resolution computer tomography (HRCT) in $93.3 \%$ of patients with asbestos exposure. Pleural hyalinosis was found in all patients; among them, 20 subjects (44.4\%) had diffuse pleural thickening. As for radiological changes, 7 subjects $(15.5 \%)$ had irregular opacities grade $0 / \mathrm{s} 1$; in 21 subjects $(46.7 \%)$ mild radiological signs of asbestosis (classification s1/0 or s1/s1) were seen; and 17 patients $(37.8 \%)$ had a higher grade of asbestosis (in the range of $\mathrm{s} 1 / \mathrm{s} 2-\mathrm{t} 3 / \mathrm{u} 2)^{25)}$.

Thirty-seven patients, formerly exposed to silica (36 men, 1 woman, mean age $69.1 \pm 2.9 ; 13.5 \%$ smokers), had worked as metal ore miners, tunnelers, foundry workers or stone cutters for an average of $24.8 \pm 3.1 \mathrm{yr}$. According to the findings on the chest radiographs, 17 subjects (45.9\%) had simple silicosis in the range $\mathrm{p} 2-\mathrm{r} 3$, and 20 subjects (54.1\%) had complicated silicosis in the range of A-C ${ }^{25}$.

Twenty-seven control subjects (18 men, 9 women, mean age $66.0 \pm 6.9 \mathrm{yr} ; 14.8 \%$ smokers) had never been occupationally exposed to fibrogenic dusts nor diagnosed with lung fibrosis. They had previously worked as office employees and safety inspectors.

Exclusion criteria in all groups were the exacerbation of chronic bronchitis, treatment with antibiotics during the past 2 months, and smoking in the morning before the examination.

The number of subjects diagnosed with chronic bronchitis (COPD grade 0), COPD (grade I-IV) ${ }^{26)}$ and asthma in the asbestos-exposed group was $5(11.1 \%), 0(0 \%)$ and $1(3.5 \%)$ subject; in the silica-exposed $3(8.9 \%), 10(27.0 \%)$ and $2(6.9 \%)$ subjects. In the controls 2 subjects $(7.4 \%)$ had COPD grade 0 , one $(3.7 \%)$ COPD grade I; no person had asthma.

Subjects with systemic disorders were present in all groups examined. The percentage of those diagnosed with atherosclerosis in asbestos-exposed, silica-exposed and controls was $60.0,78.4$ and 59.3, respectively. The percentage of subjects from the same groups previously diagnosed with cancer was $11.1(2 \times$ kidney, $2 \times$ breast, $1 \times$ blood), $15.6(3 \times$ lung, $2 \times$ colon, $1 \times$ prostate, $1 \times$ urinary $)$ and $7.4(1 \times$ larynx, $1 \times$ prostate $)$, respectively. Systemic inflammatory diseases were rare; ulcerative colitis was diagnosed in one asbestos-exposed patient, and rheumatoid arthritis in one patient from both the asbestos and silicaexposed groups; in no subject in the control group.

All 3 groups of subjects were examined according to the following scheme: physical examination and a standardized questionnaire with personal and occupational history, treatments, dietary habits, and alcohol intake. In addition, smoking, meals and alcoholic beverages consumed during the day proceeding the day of examination and biological sample collection were recorded.

\section{Blood and urine analysis}

Blood and a spot urine samples were taken between 8 and 12 a.m. for following parameters: erythrocyte sedimentation (ESR), cholesterol, triacylglyceroles, glycohemoglobin, creatinine and liver enzymes in the blood; urinalysis; in addition LTs B4, C4, D4 and E4 were measured in plasma and urine.

\section{EBC collection}

EBC collection was performed within the following 15-20 min with EcoScreen, Jaeger, for the analysis of LTs B4, C4, D4 and E4. All subjects (wearing a nose-clip) breathed tidally through a mouthpiece connected to the condenser $\left(-20^{\circ} \mathrm{C}\right)$, where vapors, aerosols and moisture condense along the walls of the tube ${ }^{27)}$. A constant volume of 1201 of exhaled air was maintained. Immediately after the sample collection, its volume was measured, and 250 pg of $\mathrm{LTE}_{4}-d_{3}$ was added to $1 \mathrm{ml}$ of EBC as deuterium labelled internal standard (stable-isotope-dilution assay). Samples were immediately frozen to $-80^{\circ} \mathrm{C}$ and stored for a period not exceeding 2 months. Lung functions were measured using a body plethysmograph (Jaeger, Germany) in all subjects. The study was agreed by the ethical committee and carried out according to the Helsinki Declaration; all subjects signed the informed consent.

\section{Analysis of leukotrienes}

Analysis of leukotrienes was performed as previously described ${ }^{28)}$. Briefly, the method consists of a pretreatment step, solid-phase extraction (SPE) for rapid and effective isolation of biomarkers from the biological matrices (EBC, plasma and urine) and a detection method using 
liquid chromatography - electrospray ionization - tandem mass spectrometry (LC-ESI-MS/MS). The concentration of LTs was expressed both in the total sample and per $\mathrm{ml}$ of EBC sample to enable an easier comparison among laboratories. Contamination of the EBC with saliva eicosanoids and aldehydes was excluded by measuring the concentration of $\alpha$-amylase (UV-VIS absorption spectroscopy).

\section{Statistical methods}

Both discrete and continuous variables were included in the present study. Basic descriptive statistics (mean, mode, median, range, minimum, maximum, standard deviation, skewness and kurtosis) were calculated in the case of continuous variables. Data were verified to be free of impossible and/or unexpected values. Subsequently, the normal distribution of all variables was tested using the Kolmogorov-Smirnov test. Furthermore, the Pearson product moment correlation and Spearman rank correlation were used for normally and non-normally distributed variables, respectively. Moreover, correlations were calculated separately for selected markers in all three groups. The statistical significance of the correlations was tested on three levels: $p<0.05, p<0.01$ and $p<0.001$. The one-way analysis of variance (ANOVA) with the Fisher LSD post-hoc test was used to compare differences between groups. In the event of non-normally distributed variables, the KruskalWallis test with respective post-hoc comparisons was used as a nonparametric alternative to the one-way ANOVA.

In the case of categorical variables, data were analyzed using frequency tables and the chi-square test of homogeneity. The point-biserial correlation and Spearman correlation were used to analyze the relationships between pairs of categorical and continuous variables. This approach is an alternative to the independent samples $t$-test with the same significance levels.

All analyses were conducted and verified in SPSS 17 (SPSS Inc., Chicago, IL, USA).

\section{Results}

The parameters of lung functions were significantly impaired in both groups of patients, as shown in Table 1. The average acquired EBC volume was $1.795 \pm 0.077 \mathrm{ml}$ (range 1.0-2.8) and did not differ among the groups of subjects. LTs in the EBC, plasma and urine are presented in Table 1.

In the group of patients with silicosis, only one correlation of LT D4 with RV/TLC\% $(r=-0.336, p<0.05)$, was found.

In the patients with asbestos exposure LTs have shown several correlations with the impairment of the parameters of the lung functions. In addition, asbestosis with more severe radiological signs $(\mathrm{s} 1 / \mathrm{s} 2-\mathrm{t} 3 / \mathrm{u} 2)$ had higher LT C4 and cysteinyl LTs in the EBC $(p<0.05)$ than mild asbestosis (s1/ $\mathrm{s} 0-\mathrm{s} 1 / \mathrm{s} 1$ ) (Table 2). In addition, cysteinyl LTs in EBC correlated with TLC $(-0.313, p<0.05)$ and $\mathrm{TLCO} / \mathrm{Hb}(-0.307$, $p<0.05)$; LT C4 correlated with TLC $(-0.358, p<0.05)$.

The correlations of LTs levels in 3 different matrices, i.e. EBC, plasma and urine were calculated first in the total group of the subjects. It was found that LT D4 in the EBC that was elevated in the patients correlated with urine $(\mathrm{r}=0.254, p<0.01)$ and plasma LT D4 levels $(\mathrm{r}=0.435$, $p<0.001)$; and LT E4 in the EBC borderline correlated with its plasma level $(\mathrm{r}=0.187, p=0.051$, n.s.). Also after division into the 3 groups of subjects, correlations of LT D4 in EBC and urine were observed (Fig. 1).

ESR in both asbestos-exposed, and silica-exposed groups was higher, $17.9 \pm 4.6(p=0.002), 19.9 \pm 5.4$ $(p<0.001)$, respectively, than in controls with $7.4 \pm 2.4$. ESR correlated with LT C4, in the EBC $(\mathrm{r}=0.227, p<0.05)$.

No significant difference among the 3 groups was seen for mean cholesterol, triacylglyceroles, glycohemoglobin or liver tests. As for extra-pulmonary disorders and treatments in the patients with pneumoconioses, they only rarely showed a positive correlation with the elevated markers in plasma and urine, as shown in Table 3. In addition, several negative correlations were found, especially for LT C4 (data not shown).

Alcohol intake in $\mathrm{g} / \mathrm{week}$, diet regimen (quantity of fruits, vegetables, eggs, meat portions, butter/animal fat use per week) and diet on the day preceding the examination did not show a correlation with the concentration of LTs in any biological matrix.

\section{Discussion}

This study confirmed the elevation of LT D4 in the patients with silica and asbestos-induced diseases in studies that involved EBC analysis only ${ }^{16,17)}$. In addition, cysteinyl LTs were elevated. Lehtonen ${ }^{15}$ found increase of LT B4 in patients with asbestosis, which finding differed from our previous study in 92 asbestos-exposed subjects ${ }^{17)}$, where about $76 \%$ of patients had pleural hyalinosis and $61 \%$ interstitial lung fibrosis. In contrast, in recent study, hyalinosis and/or asbestosis were present in all subjects. This may explain why this time the elevation of LT B4 was detected.

However, our negative finding for LT B4 in the EBC of patients with silicosis was repeated ${ }^{16)}$, in contradiction to the Shimbori experimental study ${ }^{12)}$. It was in closer agree- 
Table 1. Lung functions and leukotrienes in the exhaled breath condensate (EBC), plasma and urine in subjects with asbestosis, silicosis and control subjects

\begin{tabular}{|c|c|c|c|c|c|c|}
\hline & \multicolumn{3}{|c|}{ Arithmetic mean \pm confidence interval } & \multicolumn{3}{|c|}{$p$} \\
\hline & Asbestos & Silica & Controls & $\begin{array}{c}\text { Asbestos vs. } \\
\text { Controls }\end{array}$ & $\begin{array}{l}\text { Silica vs. } \\
\text { Controls }\end{array}$ & $\begin{array}{c}\text { Asbestos vs } \\
\text { Silica }\end{array}$ \\
\hline $\mathrm{PEF}^{\mathrm{a}}$ & $6.2 \pm 0.6$ & $6.9 \pm 0.8$ & $8.6 \pm 1.2$ & $p<0.001$ & 0.008 & n.s. \\
\hline $\mathrm{PEF} \%{ }^{\mathrm{a}}$ & $92.7 \pm 6.9$ & $88.9 \pm 9.6$ & $117.6 \pm 11.9$ & $p<0.001$ & $p<0.001$ & n.s. \\
\hline $\mathrm{FVC}^{\mathrm{a}}$ & $2.8 \pm 0.3$ & $3.4 \pm 0.3$ & $3.9 \pm 0.5$ & $p<0.001$ & 0.032 & 0.004 \\
\hline $\mathrm{FVC} \%{ }^{\mathrm{a}}$ & $93.9 \pm 6.7$ & $91.8 \pm 8.6$ & $115.2 \pm 5.9$ & $p<0.001$ & $p<0.001$ & n.s. \\
\hline FEV1 \% ${ }^{a}$ & $88.6 \pm 6.5$ & $84.3 \pm 9.1$ & $117.8 \pm 7.9$ & $p<0.001$ & $p<0.001$ & n.s. \\
\hline FEV1/FVC \% ${ }^{b}$ & $75.1 \pm 2.1$ & $70.4 \pm 3.6$ & $80.8 \pm 3.1$ & 0.005 & $p<0.001$ & n.s. \\
\hline MMEF $25^{\mathrm{b}}$ & $0.512 \pm 0.083$ & $0.638 \pm 0.097$ & $1.1 \pm 0.2$ & $p<0.001$ & 0.002 & n.s. \\
\hline MEF $25-75 \%^{a}$ & $50.2 \pm 6.1$ & $54.5 \pm 8.7$ & $94.5 \pm 12.6$ & $p<0.001$ & $p<0.001$ & n.s. \\
\hline $\mathrm{TLC}^{\mathrm{a}}$ & $5.1 \pm 0.4$ & $6.2 \pm 0.4$ & $6.4 \pm 0.5$ & $p<0.001$ & n.s. & $p<0.001$ \\
\hline TLC $\%{ }^{a}$ & $90.9 \pm 5.1$ & $95 \pm 5.4$ & $106.9 \pm 5.6$ & $p<0.001$ & 0.007 & n.s. \\
\hline $\mathrm{RV}^{\mathrm{a}}$ & $2.3 \pm 0.2$ & $2.7 \pm 0.3$ & $2.4 \pm 0.3$ & n.s. & n.s. & 0.022 \\
\hline $\mathrm{RV} / \mathrm{TLC} \%{ }^{\mathrm{a}}$ & $45.1 \pm 2.5$ & $43.5 \pm 3.6$ & $37.6 \pm 4.6$ & 0.004 & n.s. & n.s. \\
\hline $\mathrm{TLCO} / \mathrm{Hb} \%^{\mathrm{a}}$ & $67.5 \pm 5.7$ & $64.3 \pm 6.4$ & $87.9 \pm 6.4$ & $p<0.001$ & $p<0.001$ & n.s \\
\hline LT B4 in EBC $(\mathrm{pg} / \mathrm{ml})^{\mathrm{b}}$ & $26.5 \pm 4.6$ & $19.0 \pm 1.8$ & $20.3 \pm 2.0$ & $p<0.001$ & n.s. & $p<0.001$ \\
\hline LT B4 in EBC (pg) ${ }^{b}$ & $48.3 \pm 8.8$ & $34.1 \pm 3.8$ & $35.0 \pm 4.7$ & 0.023 & n.s. & 0.005 \\
\hline LT B4 in plasma $(\mathrm{pg} / \mathrm{ml})^{\mathrm{a}}$ & $36.6 \pm 3.8$ & $33.5 \pm 3.7$ & $26.9 \pm 3.3$ & $p<0.001$ & 0.008 & n.s. \\
\hline LT B4 in urine $(\mathrm{pg} / \mathrm{mmol} \text { creatinine })^{\mathrm{b}}$ & $21.9 \pm 5.6$ & $31.8 \pm 11.6$ & $33.7 \pm 16.1$ & n.s. & n.s. & n.s. \\
\hline $\mathrm{LT} C 4$ in $\mathrm{EBC}(\mathrm{pg} / \mathrm{ml})^{\mathrm{b}}$ & $88.0 \pm 30.2$ & $70.1 \pm 6.3$ & $70.2 \pm 8.4$ & n.s. & n.s. & n.s. \\
\hline LT C4 in EBC (pg) ${ }^{\mathrm{b}}$ & $158.6 \pm 52.2$ & $126.6 \pm 14.9$ & $124.4 \pm 22.8$ & n.s. & n.s. & n.s. \\
\hline LT C4 in plasma $(\mathrm{pg} / \mathrm{ml})^{a}$ & $110.4 \pm 7.4$ & $107.5 \pm 7.4$ & $103.9 \pm 11.9$ & n.s. & n.s. & n.s. \\
\hline LT C4 in urine (pg/mmol creatinine $)^{b}$ & $27.1 \pm 5.6$ & $20.6 \pm 4.9$ & $20.8 \pm 6.8$ & n.s. & n.s. & n.s. \\
\hline LT D4 in EBC $(\mathrm{pg} / \mathrm{ml})^{b}$ & $31.9 \pm 1.8$ & $30.8 \pm 1.8$ & $23.0 \pm 1.8$ & $p<0.001$ & $p<0.001$ & n.s. \\
\hline LT D4 in EBC (pg) ${ }^{a}$ & $58.3 \pm 5.1$ & $55.9 \pm 5.3$ & $40.4 \pm 5.8$ & $p<0.001$ & $p<0.001$ & n.s. \\
\hline LT D4 in plasma $(\mathrm{pg} / \mathrm{ml})^{\mathrm{b}}$ & $32.5 \pm 2.6$ & $30.7 \pm 3.1$ & $33.4 \pm 9.7$ & n.s. & n.s. & n.s. \\
\hline LT D4 in urine ( $\mathrm{pg} / \mathrm{mmol}$ creatinine $)^{\mathrm{b}}$ & $18.9 \pm 3.0$ & $16.3 \pm 3.4$ & $14.2 \pm 4.4$ & 0.023 & n.s. & n.s. \\
\hline LT E4 in EBC (pg/ml) ${ }^{\text {a }}$ & $72.6 \pm 8.2$ & $69.8 \pm 7.6$ & $54.1 \pm 8.3$ & $p<0.001$ & 0.002 & n.s. \\
\hline LT E4 in EBC $(\mathrm{pg})^{\mathrm{b}}$ & $133.9 \pm 18.3$ & $127.4 \pm 18.1$ & $97.5 \pm 21.4$ & 0.017 & 0.044 & n.s. \\
\hline LT E4 in plasma $(\mathrm{pg} / \mathrm{ml})^{\mathrm{b}}$ & $47.1 \pm 4.8$ & $44.3 \pm 4.4$ & $37.7 \pm 3.3$ & 0.009 & n.s. & n.s. \\
\hline LT E4 in urine (pg/mmol creatinine) ${ }^{b}$ & $21.9 \pm 3.8$ & $18.4 \pm 3.6$ & $32.3 \pm 12.2$ & n.s. & n.s. & n.s. \\
\hline Cysteinyl LTs in EBC $(\mathrm{pg} / \mathrm{ml})^{\mathrm{b}}$ & $192.4 \pm 30.2$ & $170.7 \pm 9.5$ & $147.3 \pm 14.4$ & $p<0.001$ & 0.036 & n.s. \\
\hline Cysteinyl LTs in EBC (pg) ${ }^{\mathrm{b}}$ & $350.8 \pm 55.2$ & $309.9 \pm 30.8$ & $262.2 \pm 45.0$ & 0.014 & n.s. & n.s. \\
\hline Cysteinyl LTs in urine (pg/mmol creatinine) ${ }^{b}$ & $67.9 \pm 11.5$ & $55.3 \pm 11.06$ & $67.3 \pm 21.8$ & n.s. & n.s. & n.s. \\
\hline Cysteinyl LTs in plasma $(\mathrm{pg} / \mathrm{ml})^{\mathrm{a}}$ & $189.9 \pm 10.6$ & $182.6 \pm 10.2$ & $175.0 \pm 8.2$ & n.s. & n.s. & n.s. \\
\hline
\end{tabular}

PEF - peak expiratory flow, \% - percent predicted, FVC - forced vital capacity, FEV1 - forced expiratory volume in $1 \mathrm{~s}$, MEF $25-75$ maximal expiratory flow rate at $25-75 \%$ of the vital capacity, TLC - total lung capacity, RV - residual volume, TLCO - diffuse lung capacity for carbon monoxide, EBC - exhaled breath condensate, LT- leukotriene, cysteinyl LTs (leukotrienes C4, D4 + E4), n.s. - non significant.

${ }^{\mathrm{a}} p$-values are provided for ANOVA with LSD post-hoc test.

${ }^{\mathbf{b}} p$-values are based on the Kruskal-Wallis and respective post-hoc tests.

ment with an earlier experimental study demonstrating that silica exposure resulted in a decreased both LT B4 and LT C4 production from alveolar macrophages, suggested to be a regulatory mechanism to counterbalance enhanced TNF-alpha production during silicosis ${ }^{29)}$. Unfortunately, we are not aware of any other human studies of the EBC in the silicotics for the comparison with our results.

In addition to EBC, several LTs in plasma and urine of the patients were elevated comparing to the controls.

In the patients with pneumoconioses, markers in EBC were not positively correlated with any extra-pulmonary disease. As to respiratory disorders, LT C4 in EBC correlated with $C O P D$, which confirms our findings from the last studies focused on EBC analysis only ${ }^{16,17)}$. The most important result of this study is the fact that EBC markers in the patients with pneumoconiosis appear to primarily 
Table 2. Parameters of lung functions and leukotrienes in EBC in subjects with asbestosis according to the grade of asbestosis

\begin{tabular}{|c|c|c|c|c|c|}
\hline \multirow[t]{2}{*}{ Parameter } & \multicolumn{2}{|c|}{$\begin{array}{c}\text { Asbestosis } \\
\text { ILO classification } \mathrm{s} 1 / \mathrm{s} 0-\mathrm{s} 1 / \mathrm{s} 1 \quad(\mathrm{n}=21)\end{array}$} & \multicolumn{2}{|c|}{$\begin{array}{c}\text { Asbestosis } \\
\text { ILO classification s1/s2-t3/u2 (n=17) }\end{array}$} & \multirow[t]{2}{*}{$p$} \\
\hline & Arithmetic mean & Standard Deviation & Arithmetic mean & Standard Deviation & \\
\hline TLC & 5.54 & 0.32 & 4.27 & 0.23 & 0.003 \\
\hline TLC $\%$ & 94.77 & 3.33 & 81.94 & 3.75 & 0.015 \\
\hline TLCO & 5.79 & 0.41 & 4.25 & 0.45 & 0.013 \\
\hline $\mathrm{TLCO} / \mathrm{Hb}$ & 5.67 & 0.39 & 4.1 & 0.42 & 0.007 \\
\hline $\mathrm{TLCO} / \mathrm{Hb} \%$ & 71.92 & 3.43 & 57.58 & 5.17 & 0.017 \\
\hline EBC LT C4 (pg/ml) & 66.07 & 5.25 & 123.71 & 38.25 & 0.007 \\
\hline EBC LT C4 (pg) & 112.77 & 8.9 & 227.37 & 65.25 & 0.008 \\
\hline EBC Cysteinyl LTs (pg/ml) & 163.72 & 6.8 & 232.35 & 38.45 & 0.004 \\
\hline EBC Cysteinyl LTs (pg) & 283.75 & 15.08 & 427.85 & 65.83 & 0.025 \\
\hline
\end{tabular}

TLC - total lung capacity, \% - percent predicted, TLCO - diffuse lung capacity for carbon monoxide, Hb- hemoglobin, EBC - exhaled breath condensate, LT - leukotriene, ILO - International Labor Office.

Table 3. Significant correlation coefficients of LT B4, LT C4, LT D4, and LT E4 levels with disorders and treatment $(* p<0.05)$

\begin{tabular}{lllc}
\hline Marker & Group & \multicolumn{1}{c}{ Source vs. Variable } & Correlation \\
\hline LT B4 & Asbestos & Plasma vs. Vitamin C & $0.355^{*}$ \\
LT B4 & Asbestos & Plasma vs. Vitamin E & $0.355^{*}$ \\
LT C4 & Silica & EBC $(\mathrm{pg})$ vs. COPD grade 0 & $0.346^{*}$ \\
LT C4 & Silica & EBC $(\mathrm{pg} / \mathrm{ml})$ vs. COPD Grade I-IV & $0.337^{*}$ \\
LT C4 & Silica & EBC $(\mathrm{pg} / \mathrm{ml})$ vs. Ischemic Heart Disease & $0.340^{*}$ \\
LT C4 & Asbestos & Plasma vs. Steroids & $0.296^{*}$ \\
LT D4 & Silica & Urine vs. Kidney failure & $0.405^{*}$ \\
LT E4 & Silica & Urine vs. Kidney failure & $0.385^{*}$ \\
LT E4 & Silica & Urine vs. Salicylates & $0.339^{*}$ \\
LT E4 & Silica & Plasma vs. Vitamin C & $0.399^{*}$ \\
LT E4 & Silica & Plasma vs. Vitamin E & $0.362^{*}$ \\
LT E4 & Controls & Plasma vs. Nephrolithiasis & $0.472^{*}$ \\
LT E4 & Controls & Plasma vs. Fibrates & $0.406^{*}$ \\
\hline
\end{tabular}

LT - leukotriene, EBC - exhaled breath condensate, COPD - chronic obstructive pulmonary disease. Only positive correlations are presented.

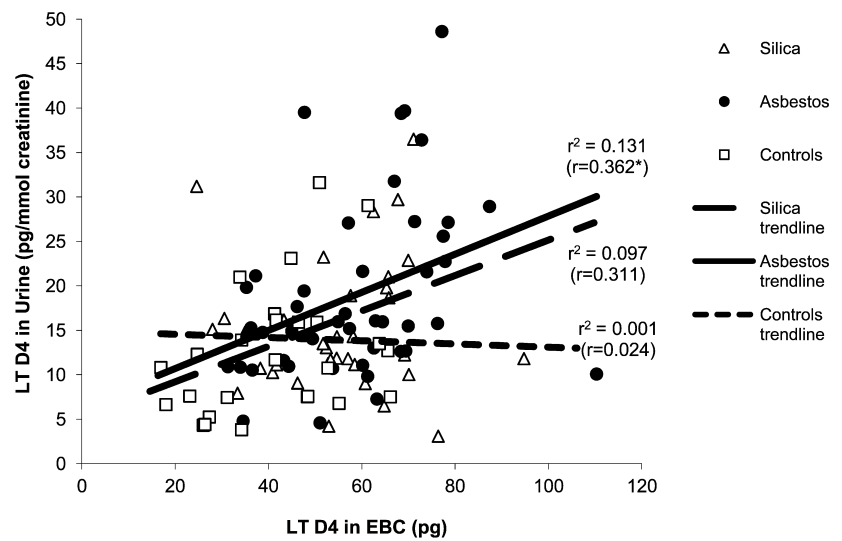

Fig. 1. Correlation of leukotriene D4 in the exhaled breath condensate $(\mathrm{EBC})$ and in urine in patients with asbestosis, silicosis and in controls. reflect these respiratory disorders. In the patients with radiological signs of asbestosis, cysteinyl LTs in EBC correlated with the impairment of TLC and TLCO/Hb, and LT C4 with TLC. These LTs in the EBC were higher in the group of subjects with more severe interstitial fibrosis than with milder asbestosis.

In urine and plasma, a positive correlation was found for kidney failure and LT D4 in the urine of the patients with silicosis, and nephrolithiasis with LT E4 in plasma of the controls.

As to disorders of the respiratory system, no other positive correlations were found in the patients with pneumoconiosis with the exception of LT C4 and COPD in the silicotics.

No significant correlation of LTs levels was found with 
smoking or dietary habits, including alcohol consumption in general, or on the day preceding the collection of biological samples.

Among the other factors studied, only a few positive correlations of LTs were observed. Pharmacological treatment (with nitrates, salicylates, antihypertensives, and corticosteroids) correlated mostly negatively in some groups of subjects (data not shown).

Surprisingly, corticosteroids correlated also positively. In one study, corticosteroids decreased LT E4 in the EBC of patients with asthma by $18 \%$ and had no effect on LT B4 in the $\mathrm{EBC}^{23)}$; LT C4 and LT D4 were not measured in that study. The effect of other pharmacological treatments on LTs is mostly unknown, according to the literature data. As LT E4 in urine is used for the evaluation of asthma, diseases such as kidney failure, and hypertension should be considered as potentially modifying factors. The same should be applied to salicylates, vitamin $\mathrm{E}$ and vitamin $\mathrm{C}$ treatment which have exhibited the most correlations with LTs.

According to the literature, LT B4 was higher in exacerbated bronchitis and after smoking. These conditions were excluded in our study. Additionally LT B4 has been described to be overproduced in ulcerative colitis, Crohn's disease, inflammatory bowel disease, rheumatoid arthritis and other disorders ${ }^{18)}$, associated with antineutrophil cytoplasmic antibody (ANCA) positivity, such as disorders due to silica and asbestos exposure ${ }^{30,31)}$. Further studies are needed to elucidate any possible relationships.

The measurement of markers in $\mathrm{EBC}$ is not commonly used in the practice of occupational medicine; nevertheless the results support its utility as a noninvasive technique for exploring the pathophysiology of lung diseases due to asbestos $^{32)}$ and silica ${ }^{33)}$. EBC collection and analysis is not considered a standard method for the medical practice yet, however repeated findings in groups of different subjects with pneumoconiosis support its usefulness. Importantly, LTs in the EBC in our patients did not significantly correlate with any other extrapulmonary disease.

$\mathrm{EBC}$ appears to be the matrix of choice for the analysis in the respiratory disorders. In addition, we report a new original finding that the impact of pneumoconiosis is not limited to the EBC. It is in accordance with the more frequent ANCA positivity and increase in ESR in silicosis and asbestosis patients.

Therefore, in addition to EBC collection, urine LT D4 and plasma LT B4 and LT E4 sampling might be used in patients with pneumoconiosis for the analysis of LTs when the equipment for EBC collection is not available. In this situation, pharmacological treatments and co-morbidities should be recorded and considered.

LC-ESI-MS/MS as a more sensitive method enables a separate detection of individual cysteinyl LTs in the EBC, plasma and urine.

\section{Acknowledgements}

We would like to thank grant P25/1LF/2 and Prof. Steve Diskin, $\mathrm{PhD}$. for linguistic assistance.

\section{References}

1) Corradi M, Gergelova P, Mutti A (2010) Use of exhaled breath condensate to investigate occupational lung diseases. Curr Opin Allergy Clin Immunol 10, 93-8. [Medline] [CrossRef]

2) Wilborn J, Bailie M, Coffey M, Burdick M, Strieter R, Peters-Golden M (1996) Constitutive activation of 5-lipoxygenase in the lungs of patients with idiopathic pulmonary fibrosis. J Clin Invest 97, 1827-36. [Medline] [CrossRef]

3) Tufvesson E, Bozovic G, Hesselstrand R, Bjermer L, Scheja A (2010) Wuttge DM Increased cysteinyl-leukotrienes and 8 -isoprostane in exhaled breath condensate from systemic sclerosis patients. Rheumatology 49, 2322-6. [Medline] [CrossRef]

4) Huang SK, Peters-Golden M (2008) Eicosanoid lipid mediators in fibrotic lung diseases: ready for prime time? Chest 133, 1442-50. [Medline] [CrossRef]

5) Carpagnano GE, Kharitonov SA, Foschino-Barbaro MP, Resta O, Gramiccioni E, Barnes PJ (2003) Increased inflammatory markers in the exhaled breath condensate of cigarette smokers. Eur Respir J 21, 589-93. [Medline] [CrossRef]

6) Ono E, Mita H, Taniguchi M, Higashi N, Tsuburai T, Hasegawa M, Miyazaki E, Kumamoto T, Akiyama K (2008) Increase in inflammatory mediator concentrations in exhaled breath condensate after allergen inhalation. J Allergy Clin Immunol 122, 768-73. [Medline] [CrossRef]

7) Klusackova P, Lebedova J, Kacer P, Kuzma M, Brabec M, Pelclova D, Fenclova Z, Navratil T (2008) Leukotrienes and 8 -isoprostane in exhaled breath condensate in bronchoprovocation tests with occupational allergens. Prostaglandins Leukot Essent Fatty Acids 78, 281-92. [Medline] [CrossRef]

8) Vannella KM, McMillan TR, Charbeneau RP, Wilke CA, Thomas PE, Toews GB, Peters-Golden M, Moore BB (2007) Cysteinyl leukotrienes are autocrine and paracrine regulators of fibrocyte function. J Immunol 179, 7883-90. [Medline]

9) James AJ, Penrose JF, Cazaly AM, Holgate ST, Sampson AP (2006) Human bronchial fibroblasts express the 5-lipoxygenase pathway. Respir Res 7, 102. [Medline] [CrossRef] 
10) Voelkel NF, Tuder RM, Wade K, Hoper M, Lepley RA, Goulet JL, Koller BH, Fitzpatrick F (1996) Inhibition of 5-lipoxygenase-activating protein (FLAP) reduces pulmonary vascular reactivity and pulmonary hypertension in hypoxic rats. J Clin Invest 97, 2491-8. [Medline] [CrossRef]

11) Peters-Golden M, Bailie M, Marshall T, Wilke C, Phan SH, Toews GB, Moore BB (2002) Protection from pulmonary fibrosis in leukotriene-deficient mice. Am J Respir Crit Care Med 165, 229-35. [Medline]

12) Shimbori C, Shiota N, Okunishi H (2010) Involvement of leukotrienes in the pathogenesis of silica-induced pulmonary fibrosis in mice. Exp Lung Res 36, 292-301. [Medline] [CrossRef]

13) Holgate ST, Peter-Golden M, Panettieri RA, Henderson WR (2003) Roles of cysteinyl leukotrienes in airway inflammation, smooth muscle function, and remodeling. J Allergy Clin Immunol 111, S18-34. [Medline] [CrossRef]

14) Ono E, Mita H, Taniguchi M, Higashi N, Tsuburai T, Miyazaki E, Kumamoto T, Akiyama K (2008) Comparison of cysteinyl leukotriene concentrations between exhaled breath condensate and bronchoalveolar lavage fluid. Clin Exp Allergy 38, 1866-74. [Medline] [CrossRef]

15) Lehtonen H, Oksa P, Lehtimaki L, Sepponen A, Nieminen R, Kankaanranta H, Saarelainen S, Jarvenpaa R, Uitti J, Moilanen E (2007) Increased alveolar nitric oxide concentration and high levels of leukotriene B-4 and 8 -isoprostane in exhaled breath condensate in patients with asbestosis. Thorax 62, 602-7. [Medline] [CrossRef]

16) Pelclová D, Fenclova $Z$, Kacer P, Navratil T, Kuzma M, Lebedova J, Klusackova P (2007) 8-isoprostane and leukotrienes in exhaled breath condensate in Czech subjects with silicosis. Ind Health 45, 766-74. [Medline] [CrossRef]

17) Pelclova D, Fenclova Z, Kacer P, Kuzma M, Navratil T, Lebedova J, Klusackova P (2007) Arachidonic acid derivatives in the exhaled breath condensate in pneumoconioses and their correlation with individual factors. Chem Listy 101, 144-6.

18) Flamand N, Mancuso P, Serezani CHC, Brock TG (2007) Leukotrienes: mediators that have been typecast as villains. Cell Mol Life Sci 64, 2657-70. [Medline] [CrossRef]

19) Funk CD (2005) Leukotriene modifiers as potential therapeutics for cardiovascular disease. Nat Rev Drug Discov 4, 664-72. [Medline] [CrossRef]

20) Klingenberg R, Hansson GK (2009) Treating inflammation in atherosclerotic cardiovascular disease: emerging therapies. Eur Heart J 30, 2838-44. [Medline] [CrossRef]

21) Vicenová B, Vopalensky V, Burysek L, Pospisek M (2009) Emerging role of interleukin-1 in cardiovascular diseases. Physiol Res 58, 481-98. [Medline]

22) Pelclova D, Navratil T, Fenclova Z, Vlckova S, Kupka K, Urban P, Ridzon P, Zikan V, Landova L, Syslova K, Kuzma M, Kacer P (2011) Increased oxidative/nitrosative stress markers measured non-invasively in patients with high 2,3,7,8-tetrachloro-dibenzo- $p$-dioxin plasma level.
Neuroendocrinol Lett 32 (Suppl 1), 71-6. [Medline]

23) Taylor GW, Black P, Turner N, Taylor I, Maltby NH, Fuller RW, Dollery CT (1989) Urinary leukotriene-e4 after antigen challenge and in acute asthma and allergic rhinitis. Lancet 1, 584-8. [Medline] [CrossRef]

24) Taniguchi M, Higashi N, Ono E, Mita H, Akiyama $\mathrm{K}$ (2008) Hyperleukotrieneuria in patients with allergic and inflammatory disease. Allergol Int 57, 313-20. [Medline] [CrossRef]

25) ILO (2002) Guidelines for the Use for the ILO International Classification of Radiographs of Pneumoconiosis. International Labour Office, Geneva.

26) Global Initiative for Chronic Obstructive Lung Disease (GOLD). Executive summary: global strategy for diagnosis, management, and prevention of COPD. http://www. goldcopd.com/. Accessed September 1, 2011.

27) Horváth I, Hunt J, Barnes PJ, Alving K, Antczak A, Baraldi E, Becher G, van Beurden WJ, Corradi M, Dekhuijzen R, Dweik RA, Dwyer T, Effros R, Erzurum S, Gaston B, Gessner C, Greening A, Ho LP, Hohlfeld J, Jöbsis Q, Laskowski D, Loukides S, Marlin D, Montuschi P, Olin AC, Redington AE, Reinhold P, van Rensen EL, Rubinstein I, Silkoff P, Toren K, Vass G, Vogelberg C Wirtz H, ATS/ERS Task Force on Exhaled Breath Condensate (2005) Exhaled breath condensate: methodological recommendations and unresolved questions. Eur Respir J 26, 523-48. [Medline] [CrossRef]

28) Syslová K, Kacer P, Kuzma M, Najmanova V, Fenclova Z, Vlckova S, Lebedova J, Pelclova D (2009) Rapid and easy method for monitoring oxidative stress markers in body fluids of patients with asbestos or silica-induced lung diseases. J Chromatogr B Analyt Technol Biomed Life Sci 877, 2477-86. [Medline] [CrossRef]

29) Mohr C, Davis GS, Graebner C, Amann S, Hemenway DR, Gemsa D (1992) Reduced release of leukotrienes B4 and C4 from alveolar macrophages of rats with silicosis. Am J Respir Cell Mol Biol 7, 542-7. [Medline]

30) Bartůňková J, Pelclova D, Fenclova Z, Sediva A, Lebedova J, Tesar V, Hladikova M, Klusackova P (2006) Exposure to silica and risk of ANCA-associated vasculitis. Am J Ind Med 49, 569-76. [Medline] [CrossRef]

31) Pelclová D, Bartunkova J, Fenclova Z, Lebedova J, Hladikova M, Benakova H (2003) Asbestos exposure and antineutrophil cytoplasmic Antibody (ANCA) positivity. Arch Environ Health 58, 662-8. [Medline] [CrossRef]

32) Pelclová D, Fenclova Z, Kacer P, Kuzma M, Navratil T, Lebedova J (2008) Increased 8-isoprostane, a marker of oxidative stress in exhaled breath condensate in subjects with asbestos exposure. Ind Health 46, 484-9. [Medline] [CrossRef]

33) Pelclová D, Fenclova Z, Syslova K, Vlckova S, Lebedova J, Pecha O, Belacek J, Navratil T, Kuzma M, Kacer P (2011) Oxidative stress markers in exhaled breath condensate in lung fibroses are not significantly affected by systemic diseases. Ind Health 49, 746-54. [Medline] [CrossRef] 